\title{
SOLUBILITY AND DISSOLUTION RATE ENHANCEMENT OF EZETIMIBE BY SOLID DISPERSION AND PELLETIZATION TECHNIQUES USING SOLUPLUS AS CARRIER
}

\author{
VISWANADH KUNAM1, VIDYADHARA SURYADEVARA², DEVALA RAO GARIKAPATI ${ }^{3}$, VENKATA BASAVESWARA \\ RAO MANDAVA ${ }^{4}$, RLC SASIDHAR 5
}

1,2,5Department of Pharmaceutics, Chebrolu Hanumaiah Institute of Pharmaceutical Sciences, Chandramoulipuram, Chowdavaram, Guntur 522019, Andhra Pradesh, India, 3Department of Pharmaceutical Analysis, KVSR Siddhartha College of Pharmaceutical Sciences, Siddhartha Nagar, Vijayawada 520010, ${ }^{4}$ Department of Pharmacy and Chemistry, Chairman, BOS, Chemistry and Pharmacy, Krishna University, Machilipatnam 521001, Krishna Dist., Andhra Pradesh, India

Email: viswanadhkunam9@gmail.com

Received: 05 Feb 2019, Revised and Accepted: 11 Apr 2019

ABSTRACT

Objective: In the present investigation, an attempt was made to improve the surface characters and solubility of the drug by solid dispersion and coating it on the nonpareil sugar beads as pellets.

Methods: Ezetimibe solid dispersions were prepared by kneading method using soluplus. Crospovidone was added as a disintegrant in pellets. Ezetimibe pellets were prepared by dissolving soluplus and crospovidone in ethanol in different ratios and coated on nonpareil sugar beads as a drug layer by pan coating technique. Various physicochemical parameters like particle size, friability, angle of repose and drug content were evaluated for the prepared solid dispersions and pellet formulations. In vitro dissolution studies were carried out in 1\% SLS using USP apparatus II. FTIR and SEM analysis were performed for solid dispersions, pellet formulations and its polymers to determine the interactions and surface characteristics.

Results: The physicochemical parameters were within the specified I. P limits. It was observed that the solid dispersion formulation $\mathrm{ED}_{5}$ showed better dissolution rate to the extent of 1.07 folds and 1.95 folds when compared to a marketed formulation and the pure drug, respectively. Similarly, pellet formulation $\mathrm{EP}_{5}$ containing 1:5 ratio of ezetimibe to soluplus showed an improved dissolution rate to the extent of 1.173 folds and 2.136 folds when compared to the marketed formulation and the pure drug, respectively. FTIR analysis revealed that there was no major interaction between the drug and the excipients.

Conclusion: From the present study, it was observed that the solubility of ezetimibe was enhanced by soluplus in pellet formulations when compared to solid dispersions.

Keywords: Ezetimibe, Soluplus, Crospovidone, HPMC E5, Solid dispersions, Pellets

(C) 2019 The Authors. Published by Innovare Academic Sciences Pvt Ltd. This is an open access article under the CC BY license (http://creativecommons.org/licenses/by/4.0/) DOI: http://dx.doi.org/10.22159/ijap.2019v11i4.32274

\section{INTRODUCTION}

Multiparticulate oral drug delivery systems have acquired a center stage in the arena of pharmaceutical research and development, thus provide greater opportunities in extending the first step of future pharmaceutical development. Multiparticulate drug delivery systems include pellets, granules, microparticles (like microspheres, microcapsules, nanoparticles), mini tablets, mini depots, multiparticulate pulsatile drug delivery systems. Pelletized dosage forms date back to the 1950s, when the first product was introduced to the market. In 1949, research scientists of SmithKline and French developed tiny drug pellets that are filled into capsules. Since then, these dosage forms have gained considerable popularity because of their distinct advantages such as enhancement of drug dissolution; ease of coating with desirable release characteristics like sustained, controlled, delayed, site-specific or pulsatile delivery of drug from coated pellets; uniform packing; ease of capsule filling because of better flow properties due to its spherical shape; even distribution in the GI tract and less GI irritation. Pellets are obtained from diverse starting materials of fine powders or granules of bulk drugs and excipients utilizing different pelletization techniques [1]. Pellets intended for oral use are administered in the form of hard gelatin capsules or disintegrating tablets which quickly liberate their contents in the stomach and gets distributed throughout the gastrointestinal tract without loss of the depot effect and acts as selfcontained depots [2, 3]. Pellets are prepared by different pelletization techniques like agitation by balling, compaction by compression and extrusion-spheronization, layering and globulation by spray drying and spray congealing.

In the present experiment, nonpareil sugar beads were coated with drug solution by layering technique. A well-controlled pelletization technique in which drug is layered onto starter seed materials which are coarse material or nonpareil, in powder, solution or suspension form with the aid of binder that assists heterogeneous pellets, consists of an inner core region and an outer shell region of a different composition [4, 5]. The nonpareil seeds must have spherical shape, smooth surface, the uniform particle size distribution for uniform coating [6]. The concentration of the binder is based on the choice of the drug because it influences physical as well as the mechanical properties of pellets and drug release from coated pellets. Commonly used binders include gelatin, povidone, carboxymethyl cellulose, hydroxyl propyl methyl cellulose, hydroxypropyl cellulose, sodium CMC, maltodextrins. Layering is classified into three categories: direct pelletizing, powder layering and solution or suspension layering $[7,8]$. Materials suitable for use as starter cores in the production of coated pellets include sugar spheres consisting of saccharides and its derivatives like sugars, sucrose-starch mixtures, oligosaccharides and polysaccharides, microcrystalline cellulose spheres, pure drug crystals. Polymers which are plastic resins, inorganic substances like silica glass, hydroxyapatite and organic substances like activated carbon, acids like citric, fumaric, tartaric, ascorbic acids etc. can be employed [9].

Ezetimibe is a BCS class II drug. It is an antihyperlipidemic drug and it helps in lowering the cholesterol $[10,11]$. It actually localizes at the brush borders of the villi in the small intestine region and prevent absorption of the cholesterol from the intestine. It binds to a carrier of cholesterol absorption, the Niemann-Pick C1-Like 1 (NPC1L1) protein on the gastrointestinal tract epithelial cells and in hepatocytes thus decreasing the LDL in the body leading to the prevention of various life-threatening diseases. It has a poor aqueous solubility, which leads to its limited dissolution resulting in poor bioavailability (35-65\%). 
The main aim of the present investigation was to formulate ezetimibe solid dispersions and fast dissolving pellets by using nonpareil sugar beads as inert core material with soluplus as binder and solubility enhancer, crospovidone as disintegrant and ethanol was used as solvent to prepare the coating suspension to coat on the sugar beads as a drug layer by pan coating technique.

\section{MATERIALS AND METHODS}

\section{Materials}

Ezetimibe was a gift sample from Pellets Pharma Ltd., Hyderabad. Soluplus, ethanol and HPMC E5 were procured from SD Fine Chem. Ltd., Mumbai. Crospovidone was a gift sample from M/S NATCO Pharma Ltd., Hyderabad.

\section{Methods}

\section{Preparation of solid dispersions by kneading method}

Solid dispersions of ezetimibe in different concentrations of soluplus were prepared by kneading method. The required quantities of drug and soluplus were dissolved in the solvent ethanol to get a clear solution in a dry mortar. The mixture was kneaded for 30 min by continuous trituration. Small volume of the solvent was added to maintain the mixture as thick slurry during the kneading process. Trituration is continued until a dry mass was obtained. The mass obtained was further dried at $50{ }^{\circ} \mathrm{C}$ for 1 hour in a hot air oven. The dried product was powdered and passed through mesh no. 100 in each case [12, 13]. Various solid dispersions and their drug to carrier ratios are indicated in table 1.

Table 1: Composition of ezetimibe solid dispersions prepared by kneading method using soluplus

\begin{tabular}{lll}
\hline Formulation & Composition & Drug: Carrier ratio (Ezetimibe: Soluplus) \\
\hline $\mathrm{ED}_{1}$ & Ezetimibe: Soluplus & $1: 1$ \\
$\mathrm{ED}$ & & $1: 2$ \\
$\mathrm{ED}_{3}$ & Ezetimibe: Soluplus & $1: 3$ \\
$\mathrm{ED}$ & Ezetimibe: Soluplus & $1: 4$ \\
$\mathrm{ED}_{5}$ & Ezetimibe: Soluplus & $1: 5$ \\
\hline
\end{tabular}

\section{Preparation of pellets by pan coating method}

A dispersion of crospovidone in purified water was prepared by using half of its quantity and it was initially applied on the sugar beads by using spray gun at a pan speed of $300 \mathrm{rpm}$ while maintaining the temperature at $60{ }^{\circ} \mathrm{C}$ using IR lamp. The crospovidone coated beads were further dried at room temperature for $12 \mathrm{~h}$. This coat acts as a base coat for applying the medicament on the beads. Coating solution was prepared by dissolving ezetimibe, soluplus and remaining crospovidone in ethanol at different ratios. The crospovidone coated spheres then placed in a pan coater and coating solution was sprayed by using sprayer gun. Coating pan was operated at $300 \mathrm{rpm}$, while hot air is blown at $50{ }^{\circ} \mathrm{C}$. Then these beads were further dried at room temperature for $12 \mathrm{~h}$. The drug-coated beads were finally coated with HPMC E5 dissolved in purified water by using a spray gun at a pan speed of $300 \mathrm{rpm}$ while maintaining the temperature at 50 ${ }^{\circ} \mathrm{C}$ using IR lamp. This coat acts as a protective layer and the finally coated beads were thoroughly dried in a tray drier at $60{ }^{\circ} \mathrm{C}$ for 1 hour. Then these beads were stored in a desiccator for further use $[14,15]$. Various pellet formulations and their drug to carrier ratios are indicated in table 2 .

Table 2: Composition of ezetimibe pellet formulations prepared by pan coating method using soluplus

\begin{tabular}{lll}
\hline Formulation & Composition & Drug: carrier ratio (Ezetimibe: Soluplus) \\
\hline $\mathrm{EP}_{1}$ & Ezetimibe: Soluplus & $1: 1$ \\
$\mathrm{EP}_{2}$ & Ezetimibe: Soluplus & $1: 2$ \\
$\mathrm{EP}_{3}$ & Ezetimibe: Soluplus & $1: 3$ \\
$\mathrm{EP}_{4}$ & Ezetimibe: Soluplus & $1: 4$ \\
$\mathrm{EP}_{5}$ & Ezetimibe: Soluplus & $1: 5$ \\
\hline
\end{tabular}

\section{Evaluation of physicochemical parameters on prepared granules}

The physical parameters such as particle size, friability, angle of repose and drug content were evaluated for prepared formulations as per the standards.

\section{Particle size determination}

The average particle size of the prepared solid dispersions and pellet formulations was analyzed by sieve analysis method [16].

\section{Friability test}

Roche friabilator was used to determine the friability. Pre-weighed pellets were placed in friabilator and rotated at a speed of $25 \mathrm{rpm}$ for $4 \mathrm{~min}$. The pellets were then re-weighed after removal of fine and the percentage of weight loss was calculated.

\section{Angle of repose determination}

Angle of repose was determined by passing the solid dispersions and pellet formulations through a funnel fixed to a burette stand at a particular height $(4 \mathrm{~cm})$. A graph paper was placed below the funnel on the table. The height and radius of pile were measured [17]. Angle of repose of the formulations was calculated using a suitable formula.

$$
\text { Angle of repose }(\theta)=\tan ^{-1} \frac{\mathrm{h}}{\mathrm{r}}
$$

Where $h$ is height and $r$ is the radius of the pile.

\section{Drug content determination}

Different formulations of ezetimibe equivalent to $10 \mathrm{mg}$ was weighed and transferred into a $100 \mathrm{ml}$ volumetric flask. To this, a small quantity of methanol was added to dissolve. It was shaken occasionally for about $15 \mathrm{~min}$ and the volume was made up to 100 $\mathrm{ml}$ by adding $1 \%$ SLS. The solution was filtered and the filtrate was subsequently diluted with $1 \%$ SLS and the absorbance was measured at $232 \mathrm{~nm}$ using $1 \%$ SLS as a blank solution.

\section{In vitro dissolution studies}

The dissolution test for prepared solid dispersions and pellets was carried out in USP apparatus Type II (paddle) with $900 \mathrm{ml}$ of $1 \%$ SLS as dissolution medium. The temperature and rotations per minute (rpm) were maintained at $37 \pm 1{ }^{\circ} \mathrm{C}$ and 75 , respectively. $5 \mathrm{ml}$ samples were withdrawn at 5, 10, 15, 20, 30, 45 and $60 \mathrm{~min}$. A fresh volume of the medium was replaced with the same volume to maintain the sink conditions and the constant volume throughout the experiment. The samples withdrawn were suitably diluted with same dissolution medium and the amount of drug dissolved was estimated by ultraviolet spectrophotometer (UV $3000^{+}$) at $232 \mathrm{~nm}$. The dissolution studies were carried out for 6 times on all the formulations. 
Based on dissolution data, various dissolution parameters such as $\mathrm{T}_{50}$ and $\mathrm{DE}_{30 \%}$ first order constant and Hixon-Crowell constants were determined for various formulations. $\mathrm{T}_{50}$ is the time required for $50 \%$ of the drug to dissolve in suitable dissolution medium. It can be measured by plotting a graph taking time in minutes on $\mathrm{X}$ axis and cumulative percent drug dissolved on Y-axis. The dissolution efficiency can have a range of values depending on the time intervals chosen. In any case, constant time intervals should be chosen for comparison. The index $\mathrm{DE}_{30 \%}$ would relate to the dissolution of drug from a particular formulation after $30 \mathrm{~min}$ and could only be compared with $\mathrm{DE}_{30 \%}$ of other formulations. It was calculated using the dissolved percentage curves of the drug versus time. Here, the region between the area above the curve and the total area of the graph were used for calculation and expressed in percentage.

\section{Characterization of ezetimibe formulations}

Based on the dissolution studies, the optimized formulations were selected and FTIR studies were performed to know the drug and polymer interactions. SEM analysis was performed for pellet formulation and its polymers to know the surface characteristics.

\section{Accelerated stability studies}

The optimized formulations $\left(\mathrm{ED}_{5}\right.$ and $\left.\mathrm{EP}_{5}\right)$ were subjected to accelerated stability studies as per ICH guidelines. They were kept in separate petri dishes after preparation and stored in a thermostated oven at a temperature and relative humidity $(\mathrm{RH})$ of $25 \pm 2{ }^{\circ} \mathrm{C}$, $60 \pm 5 \% \mathrm{RH}$ for $6 \mathrm{mo}$ and $40 \pm 2{ }^{\circ} \mathrm{C}, 75 \pm 5 \% \mathrm{RH}$ for 3 mo. Then, they were evaluated for physical parameters, drug content and drug release studies.

\section{RESULTS AND DISCUSSION}

Ezetimibe solid dispersions and fast dissolving pellets were prepared by kneading method and spray coating techniques respectively. Ezetimibe was formulated as dispersions at different concentrations of soluplus; while in pellets, the drug and crospovidone concentration was maintained constant. Nonpareil sugar beads were used as inert core material for pellet formulation. Ethanol was used as a solvent to dissolve the drug and other excipients. All the formulations were prepared under identical conditions to minimize processing variables. The composition of various ezetimibe formulations was given in table 3 .

Table 3: Composition of ezetimibe solid dispersions and pellet formulations

\begin{tabular}{|c|c|c|c|c|c|c|c|c|c|c|c|}
\hline S. No. & Ingredients (mg/10 doses) & ED $_{1}$ & $\mathbf{E D}_{2}$ & $\mathbf{E D}_{3}$ & $\mathbf{E D}_{4}$ & $\mathbf{E D}_{5}$ & $\mathbf{E P}_{1}$ & $\mathbf{E P}_{2}$ & $\mathbf{E P}_{3}$ & $\mathbf{E P}_{4}$ & $\mathbf{E P}_{5}$ \\
\hline 1. & Ezetimibe & 100 & 100 & 100 & 100 & 100 & 100 & 100 & 100 & 100 & 100 \\
\hline 2. & Sugar Spheres & --- & --- & --- & --- & --- & 1000 & 1000 & 1000 & 1000 & 1000 \\
\hline 3. & Soluplus & 100 & 200 & 300 & 400 & 500 & 100 & 200 & 300 & 400 & 500 \\
\hline 4. & Crospovidone & -- & --- & --- & --- & -- & 25 & 25 & 25 & 25 & 25 \\
\hline 5. & HPMC E5 & --- & --- & --- & --- & --- & 25 & 25 & 25 & 25 & 25 \\
\hline 6. & Ethanol & q. s. & q. s. & q. s. & q. s. & q. s. & q. s. & q. s. & q. s. & q. s. & q. s. \\
\hline 7. & Purified Water & -- & --- & -- & --- & -- & q. s. & q. s. & q. s. & q. s. & q. s. \\
\hline
\end{tabular}

$\mathrm{mg}=$ milligram; q. $\mathrm{s}=$ quantity sufficient

\section{Evaluation of physicochemical parameters}

Ezetimibe formulations prepared were further evaluated for physicochemical parameters such as particle size, friability, angle of repose and drug content estimation. All the solid dispersions were having the particle size of $245-260 \mu \mathrm{m}$, while the pellet formulations were found to have the particle size in the range of $835-840 \mu \mathrm{m}$. Friability loss for all pellet formulations were within the limits i.e. $<0.8 \%$. Angle of repose values indicated that all solid dispersion formulations were having good flow characteristics with an angle of repose value ranging from $21-24^{\circ}$, whereas pellet formulations were having excellent flow properties with angle of repose 16-18 ${ }^{\circ}$ Drug content was estimated for all formulations and found to be highly uniform in range of 8.50-9.88 mg/dose. Physicochemical parameters evaluated for ezetimibe formulations indicated that all formulations were stable and possessing required limits as per literature. The values of physicochemical parameters of ezetimibe formulations were given in table 4.

Table 4: Evaluation of physicochemical parameters of ezetimibe formulations

\begin{tabular}{|c|c|c|c|c|c|}
\hline S. No. & Formulation code & $\begin{array}{l}\text { Particle size }(\mu \mathrm{m}) \\
\text { mean } \pm \text { SD }\end{array}$ & $\begin{array}{l}\text { Friability } \\
(\% \mathrm{w} / \mathrm{w})\end{array}$ & Angle of repose $\left({ }^{\circ}\right)$ & $\begin{array}{l}\text { Drug content (mg/dose) } \\
\text { mean } \pm S D\end{array}$ \\
\hline 1. & ED1 & $250 \pm 0.12$ & --- & 24 & $8.50 \pm 0.12$ \\
\hline 2. & ED2 & $255 \pm 0.46$ & --- & 23 & $9.11 \pm 0.21$ \\
\hline 3. & ED3 & $260 \pm 0.39$ & ---- & 23 & $9.18 \pm 0.19$ \\
\hline 4. & ED4 & $260 \pm 0.27$ & --- & 22 & $9.21 \pm 0.26$ \\
\hline 5. & ED5 & $245 \pm 0.36$ & --- & 21 & $9.32 \pm 0.38$ \\
\hline 6. & EP1 & $835 \pm 0.28$ & 0.2 & 18 & $9.38 \pm 0.32$ \\
\hline 7. & EP2 & $840 \pm 0.52$ & 0.2 & 18 & $9.58 \pm 0.26$ \\
\hline 8. & EP3 & $835 \pm 0.48$ & 0.1 & 17 & $9.68 \pm 0.42$ \\
\hline 9. & EP4 & $835 \pm 0.38$ & 0.12 & 17 & $9.75 \pm 0.36$ \\
\hline 10. & EP5 & $840 \pm 0.29$ & 0.12 & 16 & $9.88 \pm 0.28$ \\
\hline
\end{tabular}

$\mathrm{n}=3 ; \mu \mathrm{m}=$ micrometer; $\% \mathrm{w} / \mathrm{w}=$ percentage weight by weight; $\mathrm{SD}=$ Standard deviation

\section{In vitro dissolution studies}

Dissolution studies were conducted for all the ezetimibe fast dissolving formulations along with pure drug and the marketed formulation. Dissolution studies were performed by using USP apparatus type II (paddle type) with 1\% SLS as a medium, while maintaining bath temperature at $37 \pm 1{ }^{\circ} \mathrm{C}$ with a paddle operated at $75 \mathrm{rpm}$. Dissolution profiles indicated that ezetimibe pure drug released to the extent of $46.53 \%$ whereas the marketed formulation (Ezedoc 10) was released to the extent of $84.72 \%$ at one hour. Solid dispersions $\mathrm{ED}_{1}-\mathrm{ED}_{5}$ found to release the drug in the range of 61.53 to $90.90 \%$. The prepared fast dissolving solid dispersions tend to increase drug release from 1.322 to 1.953 folds when compared to pure drug. Pellet formulations $\mathrm{EP}_{1}-\mathrm{EP}_{5}$ were found to release the drug from 63.23 to $99.41 \%$. These fast dissolving pellet formulations tend to increase the drug release from 1.358 to 2.136 folds when compared to pure drug and 1.07 to 1.173 folds when compared to the marketed formulation. It was observed that the dissolution rate of the solid dispersion formulation $\mathrm{ED}_{5}$ showed better dissolution rate to the extent of 1.072 folds and 1.953 folds when compared to 
the marketed formulation and pure drug respectively. Similarly, formulation $\mathrm{EP}_{5}$ containing 1: 5 ratio of ezetimibe to soluplus the dissolution rate was increased to the extent of 1.173 folds when compared to the marketed formulation and 2.136 when compared to pure drug. It was observed that the rate of dissolution is greatly increased with pellet formulations than compared to solid dispersions prepared. Formulation $\mathrm{EP}_{5}$ pellets containing 1:5 drug to polymer ratio exhibited better release characteristics when compared to formulation $\mathrm{ED}_{5}$ containing 1:5 ratio of drug and polymer. This was due to the increased surface area of the pellet formulations $[18,19]$. Other studies also showed that use of soluplus as the carrier in solid dispersions and pellet formulations enhanced the solubility and hence the bioavailability of BCS Class-II drugs. [20,21] Results of the present study also justified the same. Dissolution profiles were given in fig. 1 and 2.

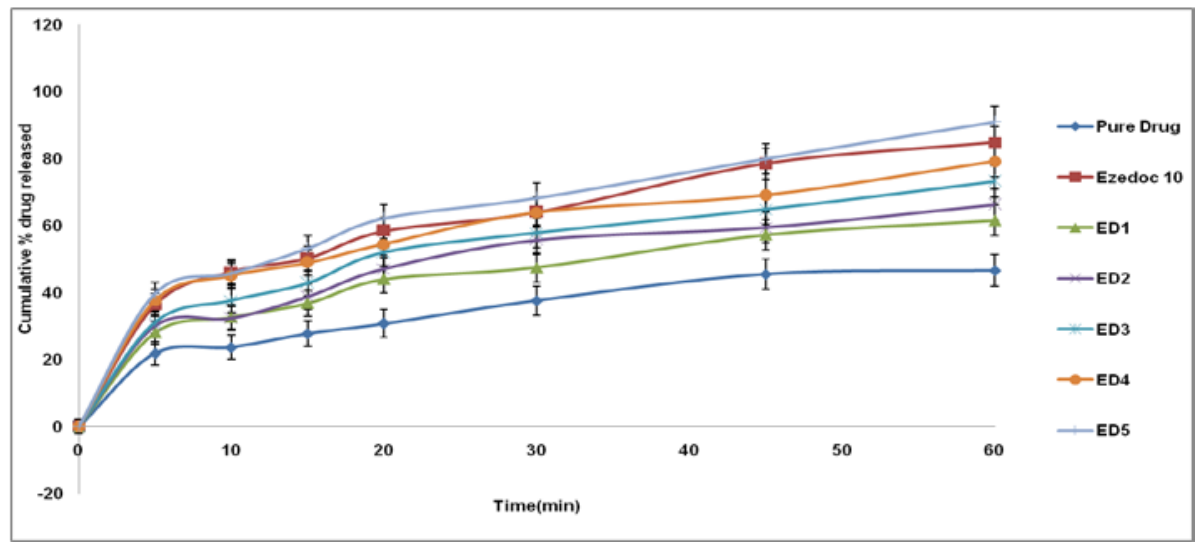

Fig. 1: Dissolution profiles of ezetimibe fast dissolving solid dispersions (Results are expressed as mean \pm SD, $n=3$ )

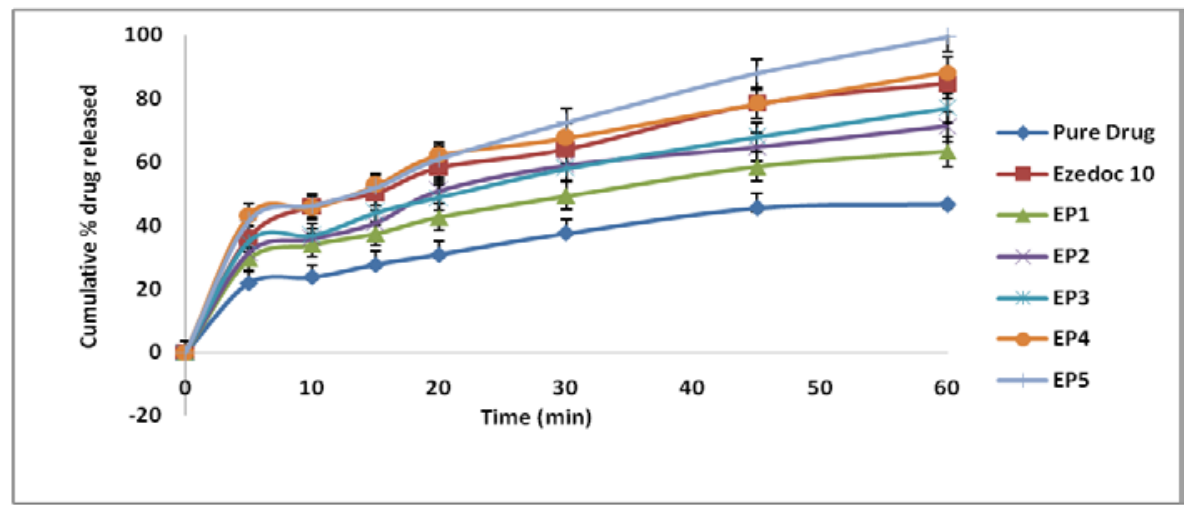

Fig. 2: Dissolution profiles of ezetimibe fast dissolving pellets (Results are expressed as mean $\pm S D, n=3$ )

Dissolution parameters such as $\mathrm{T}_{50}$ and $\mathrm{DE}_{30} \%$ values were calculated for all the formulations. $\mathrm{T}_{50}$ for solid dispersions range from 13 to $34 \mathrm{~min}$. Similarly, $\mathrm{T}_{50}$ for pellet formulation ranges from 12 to $31.5 \mathrm{~min}$. $\mathrm{DE}_{30} \%$ values for solid dispersions ranges from 35 to $48.33 \%$. $\mathrm{DE}_{30} \%$ values for pellet formulations ranges from 35.00 to $53.43 \%$. Majority of the formulations displayed first order release kinetics and were found to be linear with $\mathrm{R}^{2}$ values in the range of 0.874 to 0.982 . The Hixon crowell constants for all the formulations were found to be linear with $\mathrm{R}^{2}$ values ranging from 0.952 to 0.997 indicating that the drug release is by continuous depletion of the drug from the film formed across the spherical bead per unit weight. The results were indicated in table 5.

Table 5: In vitro dissolution kinetics of ezetimibe formulations

\begin{tabular}{|c|c|c|c|c|c|c|c|}
\hline \multirow[t]{2}{*}{ S. No. } & \multirow[t]{2}{*}{ Formulations } & \multirow[t]{2}{*}{$T_{50}(\mathrm{~min})$} & \multirow{2}{*}{$\begin{array}{l}D_{30} \\
(\%)\end{array}$} & \multicolumn{2}{|c|}{ First order } & \multicolumn{2}{|c|}{ Hixon crowell } \\
\hline & & & & $\mathbf{R}^{2}$ & $\mathrm{~K}_{1}\left(\mathrm{~min}^{-1}\right)$ & $\mathbf{R}^{2}$ & $\mathrm{~K}_{\mathrm{HC}}\left(\mathrm{mg}^{1 / 3}\right)$ \\
\hline 1 & Pure drug & & 25 & 0.874 & 0.009 & 0.958 & 0.004 \\
\hline 2 & Marketed formulation (Ezedoc 10) & 15 & 43.3 & 0.966 & 0.028 & 0.994 & 0.012 \\
\hline 3 & $\mathrm{ED}_{1}$ & 34 & 35 & 0.896 & 0.013 & 0.978 & 0.006 \\
\hline 4 & $\mathrm{ED}_{2}$ & 23 & 36.66 & 0.899 & 0.015 & 0.952 & 0.007 \\
\hline 5 & $\mathrm{ED}_{3}$ & 19.5 & 38.33 & 0.929 & 0.019 & 0.963 & 0.008 \\
\hline 6 & $\mathrm{ED}_{4}$ & 17.5 & 45 & 0.924 & 0.022 & 0.984 & 0.009 \\
\hline 7 & $\mathrm{ED}_{5}$ & 13 & 48.33 & 0.969 & 0.034 & 0.991 & 0.014 \\
\hline 8 & $\mathrm{EP}_{1}$ & 31.5 & 35 & 0.907 & 0.014 & 0.992 & 0.006 \\
\hline 9 & $\mathrm{EP}_{2}$ & 23 & 41.6 & 0.929 & 0.018 & 0.961 & 0.008 \\
\hline 10 & $\mathrm{EP}_{3}$ & 20 & 44.2 & 0.956 & 0.021 & 0.997 & 0.01 \\
\hline 11 & $\mathrm{EP}_{4}$ & 14 & 51.66 & 0.963 & 0.031 & 0.991 & 0.013 \\
\hline 12 & $\mathrm{EP}_{5}$ & 12 & 53.43 & 0.982 & 0.042 & 0.992 & 0.024 \\
\hline
\end{tabular}

$\mathrm{T}_{50}=$ Time required for $50 \%$ of drug release; $\mathrm{DE}_{30}=$ Dissolution efficiency within $30 \mathrm{~min}$; $\mathrm{R}^{2}=$ Regression coefficient; $\mathrm{K}_{1}=$ First order rate constant; $\mathrm{K}_{\mathrm{HC}}=$ Hixon crowell rate constant 


\section{Characterization studies}

\section{FTIR analysis}

The drug and excipient interactions were further characterized by IR Spectral analysis. FTIR Spectra of ezetimibe pure drug, soluplus, optimised ezetimibe solid dispersion and optimized ezetimibe pellet formulation were obtained by $\mathrm{KBr}$ pelletization process. Spectra exhibited peaks, indicating the presence of $=\mathrm{C}-\mathrm{H},-\mathrm{C}-\mathrm{F}$ and $\mathrm{C}=\mathrm{O}$, stretching and bending functional groups. Thus the FTIR Spectral analysis indicated that there were no drug interactions. The detailed spectra elucidations were shown in fig. 3, 4, 5 and 6 and indicated in table 6.

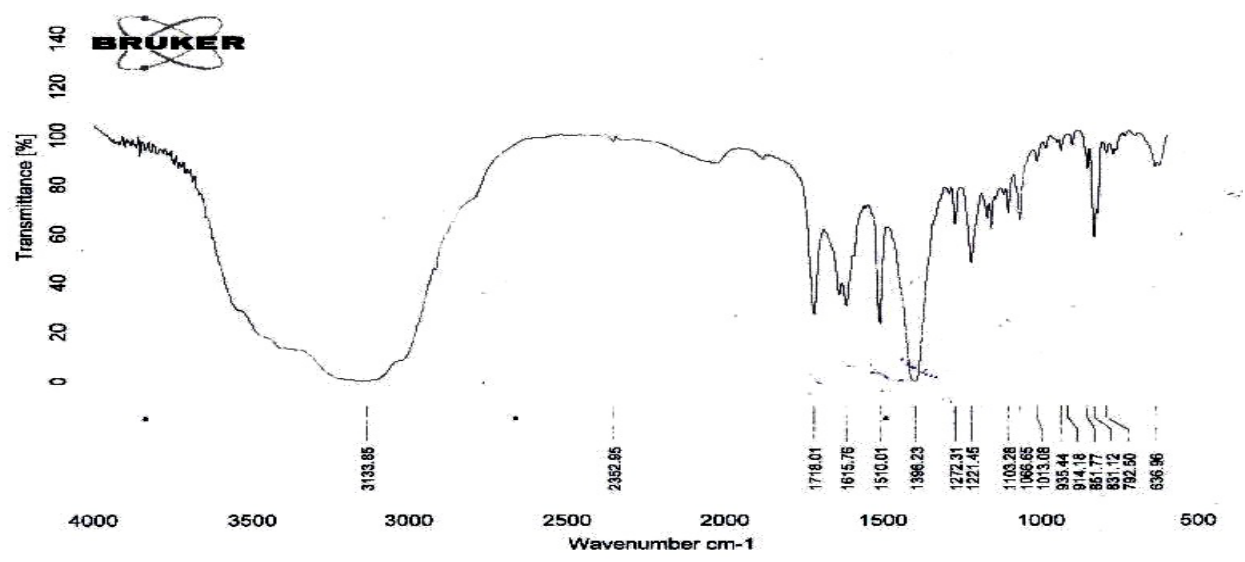

Fig. 3: FTIR interpretation of ezetimibe

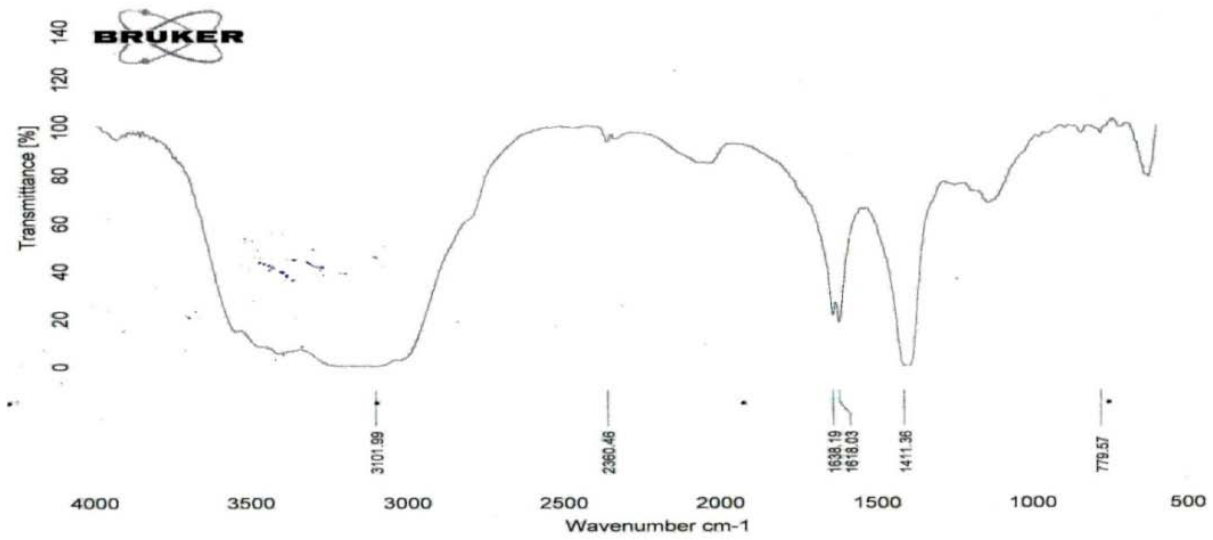

Fig. 4: FTIR interpretation of soluplus

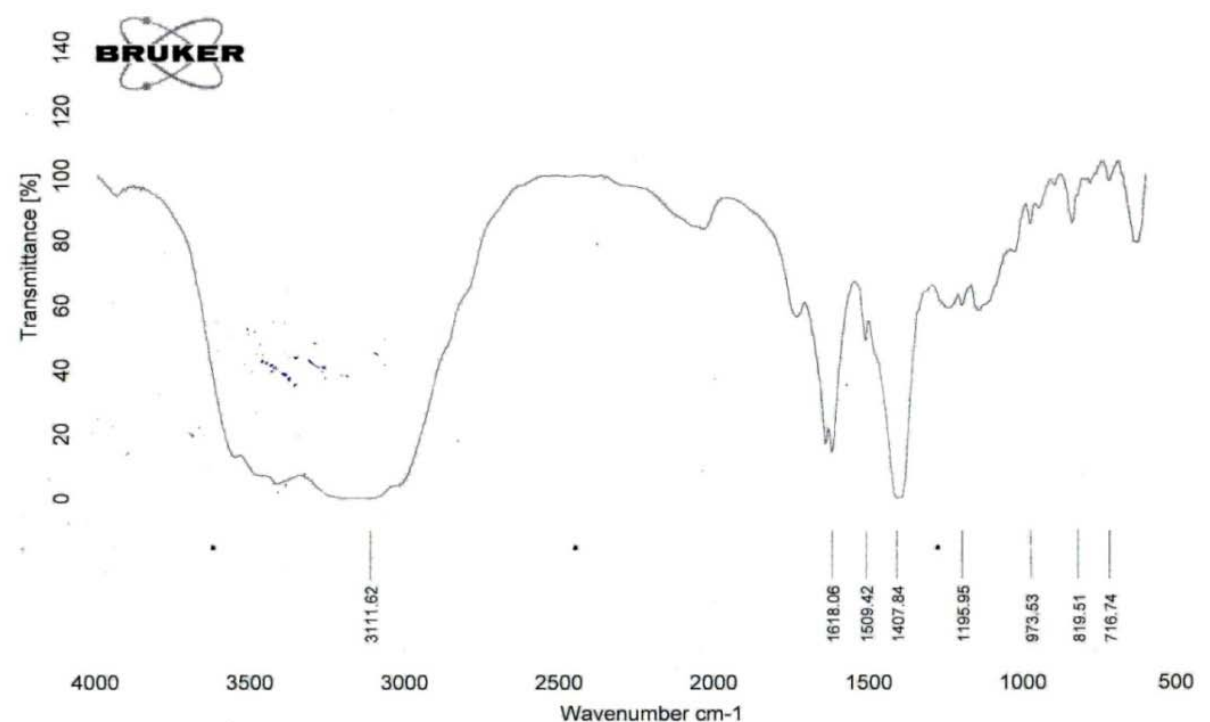

Fig. 5: FTIR spectra of optimized solid dispersion (ED5) 


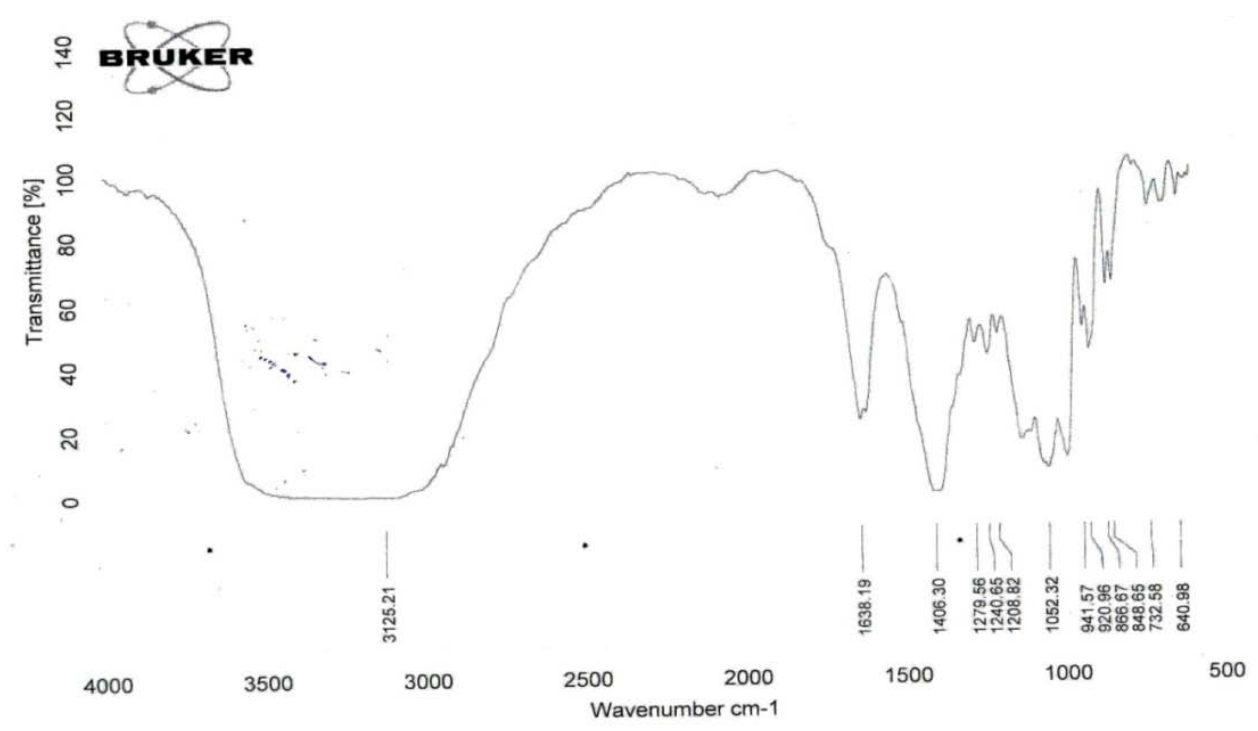

Fig. 6: FTIR spectra of optimized pellet formulation (EP5)

Table 6: FTIR spectrum interpretation for ezetimibe formulations

\begin{tabular}{lllll}
\hline Functional group & Wave number $\mathbf{( c m}^{-1} \mathbf{)}$ & & & \\
\cline { 2 - 5 } & Pure drug & Soluplus & ED5 & EP5 \\
\hline C-H Stretching & 3133.85 & 3101.99 & 3111.62 & 3125.21 \\
C=O Stretching & 1718.01 & 1638.19 & 1618.06 & 1638.19 \\
C-H Bending & 1510.01 & 1411.36 & 1407.84 & 1406.3 \\
C-F Stretching, aromatic & 851.77 & -- & 819.51 & 866.67 \\
\hline
\end{tabular}

\section{SEM analysis}

The SEM analysis revealed the structure of ezetimibe as crystalline and soluplus as spherical which were indicated in fig. 8. Solid dispersions prepared by kneading technique were found to be in the fine amorphous form of dispersion where drug is totally entrapped into soluplus. The uncoated and coated sugar beads exhibited a smooth surface with a uniform coating upon the coated pellets, thereby providing improved surface area for better dissolution rate.

\section{Scanning electron microscopy (SEM)}

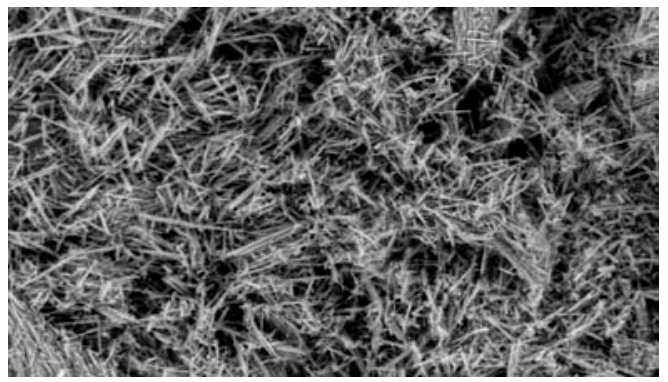

(a)

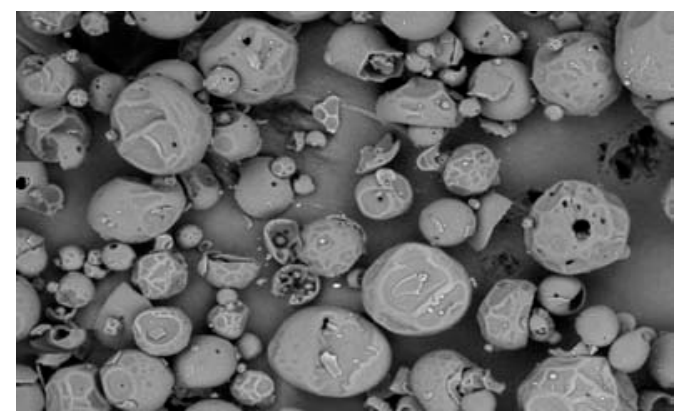

(b)

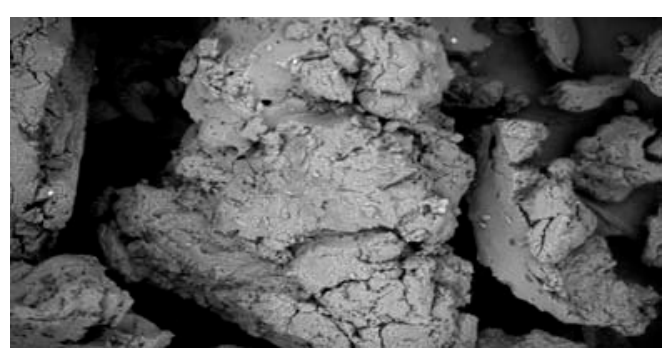

(c)

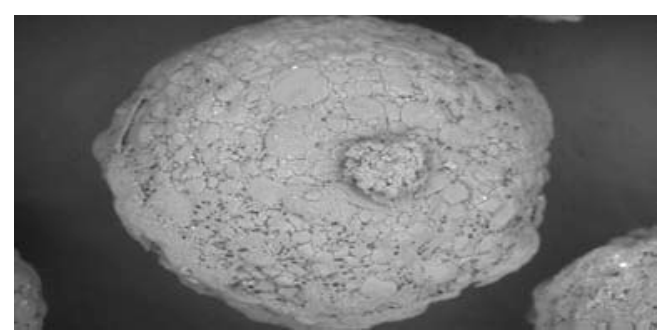

(d)

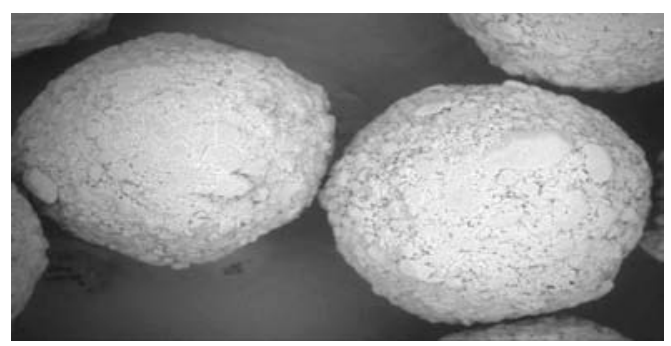

(e)

Fig. 8: Scanning electron microscopic images of (a) ezetimibe (b) soluplus, (c) solid dispersions (d) sugar spheres (e) coated spheres 


\section{Accelerated stability studies}

The optimized formulations $\mathrm{ED}_{5}$ and $\mathrm{EP}_{5}$ were subjected to accelerated stability studies as per ICH guidelines after storage at different conditions. Physical parameters and drug release studies were carried out on these formulations and the results were indicated in table 7 and fig. 9, 10 respectively.

Table 7: Parameters of formulations $\mathrm{ED}_{5}$ and $\mathrm{EP}_{5}$ under accelerated stability conditions

\begin{tabular}{|c|c|c|c|c|c|}
\hline Formulation & Storage condition & $\begin{array}{l}\text { Particle size } \\
(\mu \mathrm{m}) \\
\text { mean } \pm \text { SD }\end{array}$ & $\begin{array}{l}\text { Friability } \\
(\% \mathrm{w} / \mathrm{w})\end{array}$ & Angle of repose $\left({ }^{\circ}\right)$ & $\begin{array}{l}\text { Drug content (mg/dose) } \\
\text { mean } \pm S D\end{array}$ \\
\hline \multirow[t]{3}{*}{$\mathbf{E D}_{5}$} & Before Storage & $245 \pm 0.36$ & $\begin{array}{l}--- \\
--\end{array}$ & 21 & $9.32 \pm 0.38$ \\
\hline & $25 \pm 2{ }^{\circ} \mathrm{C}, 60 \pm 5 \% \mathrm{RH}$ & $245 \pm 0.34$ & ---- & 21 & $9.29 \pm 0.22$ \\
\hline & $40 \pm 2{ }^{\circ} \mathrm{C}, 75 \pm 5 \% \mathrm{RH}$ & $245 \pm 0.32$ & ---- & 22 & $9.27 \pm 0.39$ \\
\hline \multirow[t]{3}{*}{$\mathbf{E P}_{5}$} & Before Storage & $840 \pm 0.29$ & 0.12 & 16 & $9.88 \pm 0.28$ \\
\hline & $25 \pm 2^{\circ} \mathrm{C}, 60 \pm 5 \% \mathrm{RH}$ & $840 \pm 0.26$ & 0.11 & 16 & $9.86 \pm 0.21$ \\
\hline & $40 \pm 2{ }^{\circ} \mathrm{C}, 75 \pm 5 \% \mathrm{RH}$ & $840 \pm 0.21$ & 0.11 & 17 & $9.84 \pm 0.26$ \\
\hline
\end{tabular}

$\mathrm{n}=3 ; \mathrm{RH}=$ Relative humidity; $\mathrm{SD}=$ Standard deviation

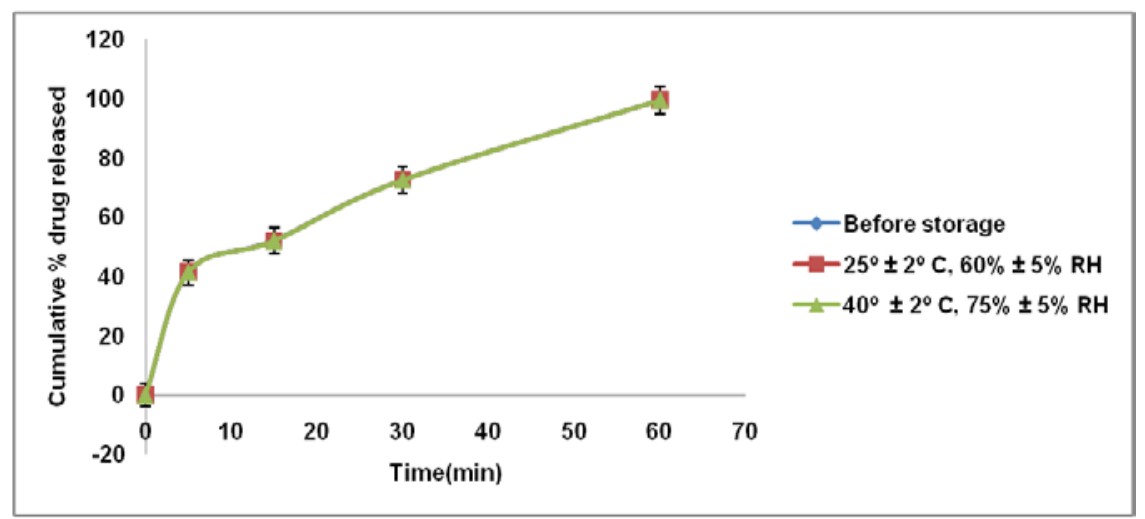

Fig. 9: Drug release studies of $\mathrm{ED}_{5}$ before and after storage at different Conditions (Results are expressed as $\mathrm{mean} \pm \mathrm{SD}, \mathrm{n}=3$ )

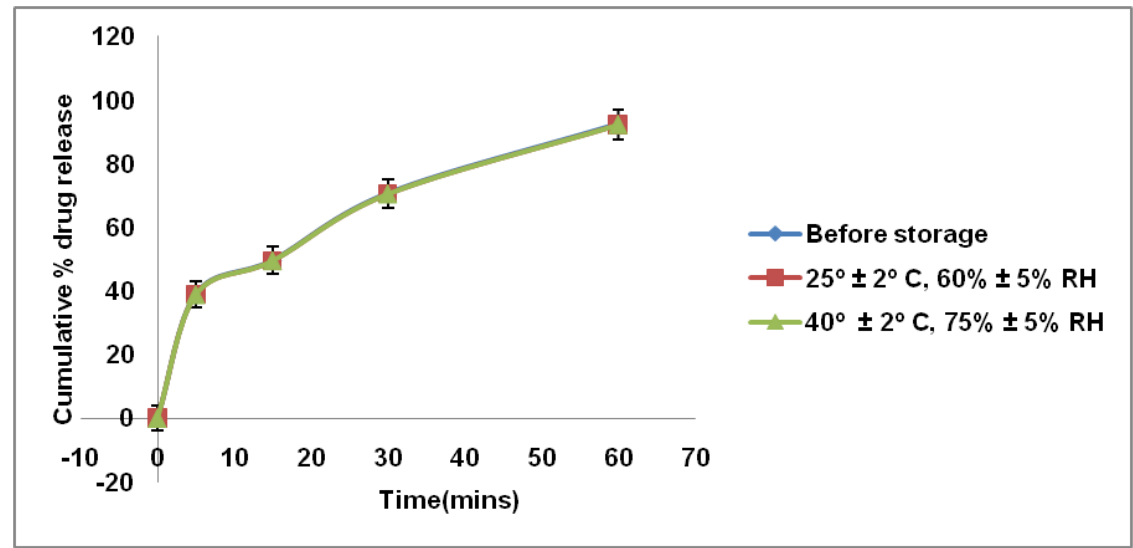

Fig. 10: Drug release studies of $\mathrm{EP}_{5}$ before and after storage at different conditions $($ Results are expressed as $\mathrm{mean} \pm \mathrm{SD}, \mathrm{n}=3$ )

There was no significant change observed in physical parameters and drug release even stability studies at various storage conditions and indicated that these formulations were found to be stable.

\section{CONCLUSION}

Ezetimibe solid dispersions and fast dissolving pellet formulations were prepared by using soluplus as a fast dissolving carrier. Among the various formulations prepared formulation $\mathrm{ED}_{5}$ and $\mathrm{EP}_{5}$ prepared by solid dispersion technique and pelletization technique exhibited faster dissolution than compared to the marketed formulation and hence they are considered as optimized formulations. Hence it is concluded that the pellet coating technique is found to be simple and stable when compared to other conventional solid dispersion techniques.

\section{ACKNOWLEDGMENT}

The authors are thankful to Pellets Pharma Ltd., Hyderabad for a gift sample of ezetimibe and management of Chebrolu Hanumaiah Institute of Pharmaceutical Sciences for providing the facilities to carry out the research work.

\section{AUTHORS CONTRIBUTIONS}

K. Viswanadh has performed the basic methodology of this work. S. Vidyadhara has guided the entire formulation and principle of the research work. G. Devala Rao has helped in the formulation studies. M. V. Basaveswara Rao helped in the interpretation of FTIR data. R. L. C. Sasidhar helped in the interpretation of SEM data. 


\section{CONFLICTS OF INTERESTS}

The authors have no conflicts of interest

\section{REFERENCES}

1. Follonier N, Doelker E. Biopharmaceutical comparison of oral multiple-unit and single unit sustained release dosage forms. STP Pharma Sci 1992;2:141-55.

2. Vial Bernasconi AC, Doelker E, Buri P. Prolonged release capsules divided and monolithic forms. STP Pharma Sci 1988;4:397-409.

3. Malinowski HJ, Smith WE. Effect of spheronization process variables on selected tablet properties. J Pharma Sci 1974;63:285-8.

4. Jackson IM, Roberts S, Timmins P, Sen H. Comparison of laboratory scale processing in the production of coated pellets. Pharm Tech Int 1989;1:29-32.

5. Gamlen MJ. Pellet manufacture for controlled release. Manuf Chem; 1985. p. 56-9.

6. Nastruzzi C, Cortesi R, Esposito E, Genovesi A, Spadoni A, Vecchio $C$, et al. Influence of formulation and process parameters on pellet production by powder layering technique. AAPS PharmSciTech 2000;12:E9.

7. Olsen K. Fluid bed equipment. In: Ghebre Sellassie I. (ed.) Pharmaceutical Pelletization Technology. Marcel and Dekker, New York; 1989. p. 39-69.

8. Bauer KH, Lehmann K, Osterwald HP, Rothgang G. Equipment for sugar coating and film coating processes coated pharmaceutical dosage forms. Medpharm Scientiphic Publishers, Stuttgart; 1998.

9. Felton LA. Film coating of oral solid dosage form. In: Swarbrick J. (ed.) Encyclopedia of Pharmaceutical Technology. Informa Healthcare 2007;3:1729-47.

10. DiPiro JT, Talbert RL, Yee GC, Marzke GR, Wells BG, Posey LM. editors. Pharmacotherapy: a pathophysiologic approach. $7^{\text {th }}$ ed. New York: The McGraw-Hill Companies, Inc; 2008.
11. Garcia Calvo M, Lisnock J, Bull HG, Hawes BE, Burnett DA, Braun MP. The target of ezetimibe is niemann-pick C1-like 1 (NPC1L1). Proc Natl Acad Sci USA 2005;102:8132-7.

12. Tirumalesh N, Chowdary KPR. Enhancement of dissolution rate of telmisartan by solid dispersion in starch 1500 and soluplus alone and in combination. Ind Am J Pharm Sci 2017;48:2274-9.

13. Mendhe AA, Kharwade RS, Mahajan UN. Dissolution enhancement of poorly water-soluble drug by cyclodextrins inclusion complexation. Int J Appl Pharm 2016;84:60-5.

14. Kausalya J, Suresh K, Padmapriya S, Anusha R, Senthilnathan B. Solubility and dissolution enhancement of Telmisartan using various techniques. Int J Pharm Tech Res 2011;33:1737-49.

15. Ashwini K, Santosh S, Vivek R, Yogesh K, Ashish J. Review on antihyperlipidemic lipophilic drugs and their novel formulation approaches. Int J Pharm Pharm Sci 2017;99:1-8.

16. Gordon RE, Rosanske TW, Fonner DE, Anderson NR, Banker GS. Granulation technology and tablet characterization. Pharmaceutical dosage forms: tablets. 1990;2:324.

17. Train D. Some aspects of the property of angle of repose of powders. J Pharm Pharmacol 1958:1;10(S1).

18. Vidyadhara S, Sasidhar RL, Sivaprasad S, Vikas S, Harika D. Dissolution rate enhancement of Irbesartan and development of fast dissolving tablets. Egypt Pharm J 2016;15:150-7.

19. Tungikar AV, Mahale NB, Rode RB. Design and characterization of solubility enhancement of Ezetimibe-a poorly water-soluble drug. World J Pharm Pharm Sci 2014;42:215-28.

20. Sandeep KV, Roop NG, Kalaiselvan R, Romi S. Design and statistical evaluation of a multiunit delivery system containing nisoldipine-soluplus ${ }^{\circledR}$ solid dispersion for hypertension chronotherapy. Int J Pharm Pharm Sci 2016;810:170-7.

21. Sanjeevani D, John D, Kiran M, Hoshmani A. Solubility enhancement of ritonavir by hot melt extrusion. Int J Pharm Pharm Sci 2016;8:309-12. 